\title{
SISTEMA DE MONITOREO Y CONTROL BASADO EN EL SOFTWARE RTMC APLICADO AL PROCESO DE BIODIGESTIÓN ANAERÓBICA
}

\section{MONITORING AND CONTROL SYSTEM BASED ON THE SOFTWARE RTMC APPLIED TO ANAEROBIC BIODIGESTION PROCESS}

\author{
PhD. Jacipt Alexander Ramón Valencia, PhD. Jarol Derley Valencia. \\ MSc. Durwin Alexis Rozo Ibáñez.
}

Universidad de Pamplona, Grupo de Investigaciones ambientales Agua, Aire y Suelo. Programa de Ingeniería Química y Ambiental.

Ciudadela Universitaria. Pamplona, Norte de Santander, Colombia. Tel.: (+577) 568 5303, Fax: (+577) 568 5303, Ext. 156.

E-mail: jacipt@unipamplona.edu.co

Resumen: Este artículo presenta el desarrollo e implementación de un sistema SCADA basado en el software RTMC (Control y Monitoreo en Tiempo Real) propio del Datalogger CR1000 de la empresa Campbell Scientific que fue utilizado para la automatización, supervisión y control de un sistema de biodigestión anaerobia en la transformación de biomasa de origen animal y vegetal, monitoreando las variables de $\mathrm{pH}$, Oxígeno Disuelto (OD), conductividad eléctrica (CE) y control de temperatura.

Palabras clave: SCADA, RTMC, Datalogger, biodigestor.

\begin{abstract}
This paper presents the development and implementation of a software-based SCADA RTMC (Control and Monitoring in Real Time) own the CR1000 Datalogger Campbell Scientific company that was used for automation, supervision and control of an anaerobic digestion system in biomass processing animal and plant monitoring variables $\mathrm{pH}$, dissolved oxygen (DO), electrical conductivity (EC) and temperature control.
\end{abstract}

Keywords: SCADA, RTMC, Datalogger, biodigester.

\section{INTRODUCCIÓN}

La digestión anaeróbica es un proceso biológico que trasforma la materia orgánica en ausencia de oxígeno y mediante la acción de los microorganismos descompone el sustrato en biogás y fertilizante orgánico [1].

Para llevar a cabo el proceso de digestión anaeróbica se utiliza un reactor discontinuo por medio de un autoclave (ver figura 2), que es un recipiente de metal, herméticamente cerrado donde se fermenta y transforma la biomasa de origen animal y vegetal, sometida a las diferentes etapas por las que atraviesa el proceso.
Con el fin de optimizar el proceso de biodigestión se implementó un sistema SCADA para mejorar la eficiencia, seguridad, confiabilidad y monitoreo de proceso, de forma secuencial utilizando un Datalogger CR1000, el cual adquiere, procesa y envía por medio de RS-232 las señales provenientes de los sensores al computador.

La HMI desarrollada está conformada por diferentes paneles como son graficas de dispersión, tabla de datos históricos, labels, imágenes y alarmas pre-establecidas en los cuales se observa la influencia de cada variable durante el proceso. 


\subsection{Proceso microbiológico y bioquímico de la digestión anaeróbica}

El proceso de digestión anaeróbica se lleve a cabo por medio de cuatro etapas principales:

- Hidrólisis

- Etapa fermentativa o acidogénica

- Etapa acetogénica

- Etapa metanogénica

La hidrólisis proporciona sustratos orgánicos para la digestión anaerobia de partículas y moléculas complejas (proteínas, hidratos de carbono y lípidos) que son hidrolizadas por enzimas extracelulares producidas por los microorganismos acidogénicos o fermentativos, como resultado se producen compuestos solubles más sencillos (aminoácidos, azúcares y ácidos grasos de cadena larga) que son fermentados por las bacterias acidogénicas dando lugar, principalmente, a ácidos grasos de cadena corta, alcoholes, hidrógeno, dióxido de carbono y otros productos intermedios; los ácidos grasos de cadena corta son transformados en ácido acético, hidrógeno y dióxido de carbono mediante la acción de los microorganismos acetogénicos; por último, los microorganismos metanogénicos producen metano a partir de ácido acético, $\mathrm{H}_{2}$ y CO [2].

En la Figura 1 se muestra las fases del proceso de digestión anaeróbica a partir de la materia orgánica compleja, pasando por la acidogénesis y finalizando con la metanogénesis.

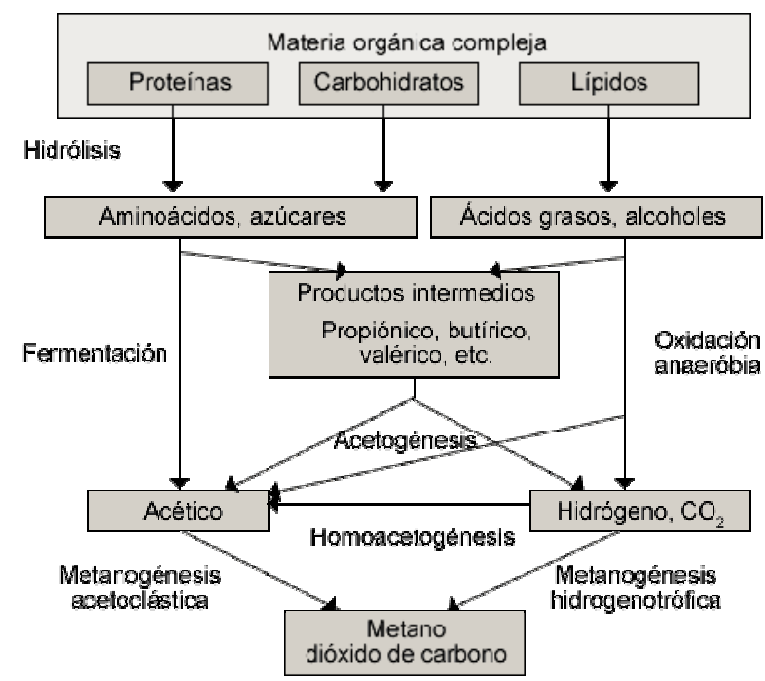

Fig. 1. Esquema de reacciones de la digestión anaeróbica.

Fuente: Pavlostathis y Giraldo-Gómez, 1991
1.2 Variables aplicadas al monitoreo de la digestión anaeróbica (DA)

Temperatura: La temperatura tiene un efecto directo sobre las propiedades fisicoquímicas de todos los componentes en el digestor y también afecta a la termodinámica y cinética del proceso biológico, determina si una reacción específica es o no favorable. Se pueden considerar tres rangos de temperatura [3]:

- Psicrofílico: $5<\mathrm{T}<20^{\circ} \mathrm{C}$ (Vavilin y Angelidaki, 2005). Aguas residuales urbanas.

- Mesofílico: $20<\mathrm{T}<40^{\circ} \mathrm{C}$ (Angelidaki y col., 2005). El más utilizado en aplicaciones industriales (Top. $35-40^{\circ} \mathrm{C}$ )

- Termofílico: $45<\mathrm{T}<65^{\circ} \mathrm{C}$ (Liu, 2003). Al elevar la temperatura, las reacciones químicas (hidrólisis, licuefacción) y biológicas transcurren a velocidades mayores.

pH: El nivel de $\mathrm{pH}$ tiene un efecto sobre la actividad enzimática en los microorganismos, ya que cada enzima está en actividad sólo en un rango específico de $\mathrm{pH}$, y tiene su actividad máxima con un $\mathrm{pH}$ óptimo [3]. Un $\mathrm{pH}$ constante indica equilibrio y estabilidad del sistema digestor y una disminución puede apuntar hacia la acumulación de ácido e inestabilidad del digestor.

La producción de gas es el único parámetro que muestra inestabilidad en el digestor más rápido que el pH. La digestión anaeróbica presenta unos niveles de $\mathrm{pH}$ óptimos entre los siguientes valores:

- Fermentativos: entre 7.2 y 7.4

- Acetogénicos: entre 7.0 y 7.2

- Metanogénicos: entre 6.5 y 7.5

Conductividad: La conductividad eléctrica de una muestra de agua es la expresión numérica de su capacidad para transportar una corriente eléctrica. Esta capacidad depende de la presencia de iones en el agua, la concentración total, la movilidad, carga o valencia y de las concentraciones relativas, así como de la temperatura a la cual se realiza el proceso.

Puesto que a mayor temperatura menor viscosidad y a menor viscosidad mayor libertad de movimiento, la temperatura también tiene una marcada influencia sobre la conductividad eléctrica de un sistema acuoso. Si bien el incremento de la conductividad eléctrica con la temperatura puede variar de un ión a otro, en general, se acepta que ésta aumenta en promedio un 3\% por cada grado centígrado que aumente la temperatura. 
Oxígeno Disuelto (OD): El oxígeno disuelto es la cantidad efectiva de oxigeno gaseoso $\left(\mathrm{O}_{2}\right)$ en el agua, expresada en términos de presencia en el volumen de agua (miligramos de $\mathrm{O}$, por litro) o de su proporción en el agua saturada (porcentaje) [4]. Cuando existe abundante cantidad de materia orgánica, el crecimiento bacteriano se ve favorecido y como consecuencia de ello los niveles de oxígeno disuelto dentro del sustrato se reducen significativamente.

\section{METODOLOGÍA}

Para el desarrollo del proyecto se utilizó un Biodigestor (autoclave) herméticamente cerrado de "flujo discontinuo" con capacidad total de 5 litros (carga completa) en el cual se deposita la biomasa como se muestra en la figura 2. La carga total de sustrato se introduce al proceso y después de un tiempo de retención finaliza el proceso en cual se descarga del efluente. Con el fin de controlar la temperatura del proceso al interior de la autoclave se implementaron 2 válvulas que permiten el ingreso y la salida de agua de refrigeración con el fin de mantener la temperatura en el rango deseado. El autoclave al interior utiliza resistencias de calentamiento y un sistema de regulación de temperatura. La toma de datos se realiza mediante los sensores que se encuentran acoplados a la tapa del autoclave y se implementó un agitador acoplado a la misma para mantener una mezcla homogénea. Se procedió a este tipo de biodigestor por su movilidad para fines educativos, procesos de pruebas - ensayos y fácil entendimiento.



Fig. 2. Biodigestor tipo discontinuo.

\section{SISTEMA SCADA}

Los sistemas SCADA (Supervisory Control And Data Adquisition) son aplicaciones de software, diseñadas con la finalidad de controlar y supervisar procesos a distancia. Se basan en la adquisición de datos de los procesos remotos.

De esta manera, los supervisores pueden visualizar e interactuar con los procesos de forma automática desde una computadora mediante representaciones gráficas de los mismos [5].

\subsection{Modelo de automatización piramidal}

Es el modelo más difundido en el ambiente de producción continua por la ISO5, consta de cinco niveles que abarcan las diferentes funciones de una planta coordinada de manera jerárquica. Cada nivel se caracteriza por un tipo de información y de procesamiento diferente, siendo necesaria la integración del proceso automatizado para incluir la comunicación interna en cada nivel, y entre niveles, para que el sistema permita ejecutar las diferentes tareas de control existentes en una empresa u proceso (figura 3 ).

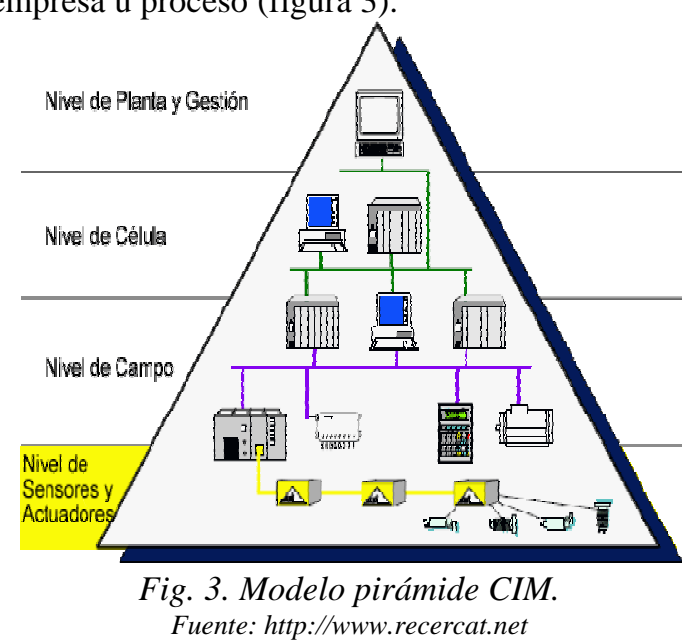

\subsection{Estructura del sistema SCADA}

Una de las etapas fundamentales para el desarrollo de este trabajo fue la implementación del sistema SCADA que trabaja los primeros tres niveles dentro del entorno piramidal de automatización integrada, permitiendo el intercambio de información entre los elementos de la propia capa o de niveles inmediatamente superior o inferior, los niveles que se trabajaron son:

- Nivel de Supervisión.

- Nivel de Control.

- Nivel de Campo o de Proceso. 
El sistema está conformado por diferentes elementos, que facilitan la funcionalidad deseada a la capa y por una configuración de la comunicación con el nivel superior $y / o$ inferior. En nuestro proyecto, los elementos son:

\section{Nivel de supervisión:}

- PC de supervisión: Se utilizó un computador convencional dotado de un paquete de softwares industriales de la Campbell Scientific (apartado 3.3), para configurar la red de supervisión e implementar el sistema SCADA.

\section{Nivel de control}

- Datalogger CR1000: Se utilizó como unidad de control local y realiza las tareas de configuración de comunicación, adquisición, procesamiento, envió de datos (variables de temperatura, oxígeno disuelto, $\mathrm{pH} \quad \mathrm{y}$ conductividad) y control de actuadores.

\section{Nivel de Proceso}

- Conjunto de sensores y actuadores: Situados a nivel de campo, se utilizan directamente en la adquisición de las variables del proceso (apartado 4.1).

\subsection{El Software}

En el proyecto se utilizó el paquete de software industrial de la marca Campbell Scientific debido a su versatilidad y prestaciones en el desarrollo de sistemas SCADA.

\subsubsection{Software PC200W}

El PC200W permite realizar un enlace de comunicación entre la información proveniente del CR1000 al PC, configuración de parámetros, protocolo de comunicación RS-232 y envió de programas al Datalogger [6].

\subsubsection{Software ShortCut (SCWin 2.9)}

El SCWin permite seleccionar los sensores, los datos de salida y el intervalo de recolección de datos en las tablas de registros, crea un diagrama de cableado y un archivo de programa para la transferencia al CR1000. También incluye un soporte para la entrada algebraica de expresiones [7, Sección 7.2].

\subsubsection{Software RTMC Pro}

Se utilizó para crear y ejecutar la HMI que proporciona monitoreo en tiempo real, capacidades de control, publicación del sistema SCADA en la web y envió de correos electrónicos basados en las alarmas establecidas [7, Sección 5.2].

\section{INTERFAZ HOMBRE MÁQUINA (HMI)}

Cuando los seres humanos y los computadores interactúan lo hacemos a través de un medio o interfaz que se define como HMI, las cuales varían ampliamente dependiendo de su aplicación. Una interfaz hombre maquina es la que permite que el usuario $\mathrm{u}$ operador del sistema de control o supervisión interactúe con los procesos [8].

El HMI (Interfaz Hombre-Máquina) desarrollada provee al operador los datos provenientes del proceso además de visualizar eventos y alarmas del mismo. El sistema proporciona graficas de dispersión, indicadores, tablas de datos históricos donde se observa el comportamiento de las variables del proceso; la información suministrada es visualizada en la página web (www.unipamplona.edu.co/dascada) basada en los softwares web publishing y Web Server de la empresa Campbell Scientific logrando obtener los datos desde cualquier lugar del mundo.

\subsection{Dispositivos para el monitoreo y visualización}

Datalogger CR1000: El CR1000 es un registrador de datos de la Campbell [9] (ver figura 4) que a su vez es el núcleo del sistema SCADA aplicado en el proyecto, se define como Unidad de Medida y control, a través de este se realizó la adquisición de señales provenientes de los sensores, el procesamiento y almacenamiento de datos e inicio de comunicación a una velocidad de exploración específica.

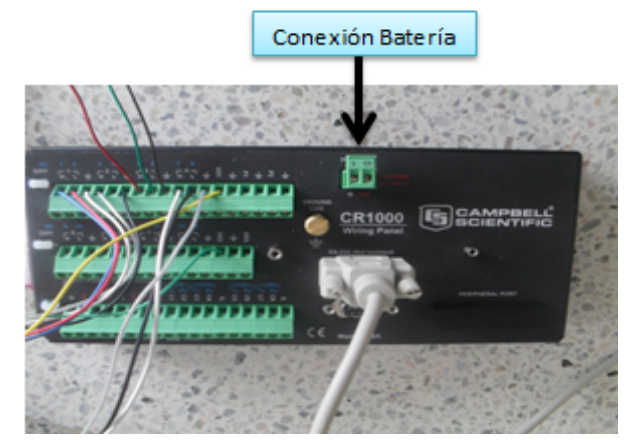

Fig.4. CR1000 Sistema de medición y control.

CS511 - L Sensor Oxígeno Disuelto: Es una sonda galvánica de la empresa Campbell Scientific [10] (ver figura 5) que produce una señal en milivoltios proporcional a la cantidad de oxígeno presente dentro del digestor. El oxígeno se difunde 
a través de la membrana hacia el cátodo, reacciona químicamente por la solución electrolítica, y se combina con el ánodo. Una corriente eléctrica se produce por esta reacción química que se convierte de microamperios a milivoltios por un resistor en línea. Un termistor en línea también proporciona una compensación automática de la temperatura.

La sonda consta de dos partes, una parte superior con el cátodo, ánodo y el cable, una parte inferior con una solución de electrolito y un tornillo de tapón en la membrana.

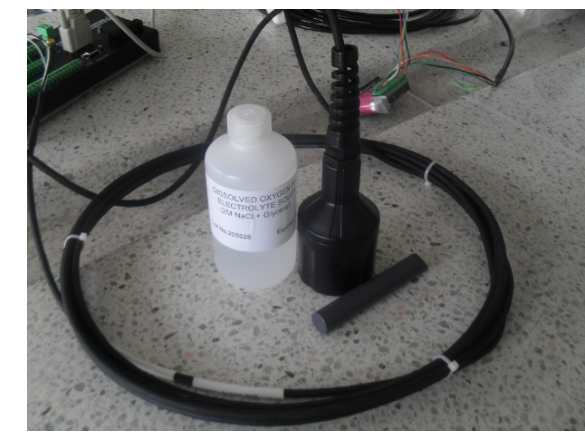

Fig. 5. CS511-L Sensor de oxígeno disuelto DO6400.

CS547A - L: El CS547 es un sensor de Temperatura y Conductividad Eléctrica (CE) de la Campbell [11] como se muestra en la figura 6, este consta de tres anillos de acero inoxidable montado en un tubo de epoxi que al pasar agua dentro, mide la resistencia de esta por excitación del electrodo central con tensión positiva y negativa, generando así una señal de conductividad en una solución o concentración total de iones presentes en una muestra acuosa. La medición de temperatura se realiza con un termistor en una configuración puente de tres hilos que está dentro del epoxi.

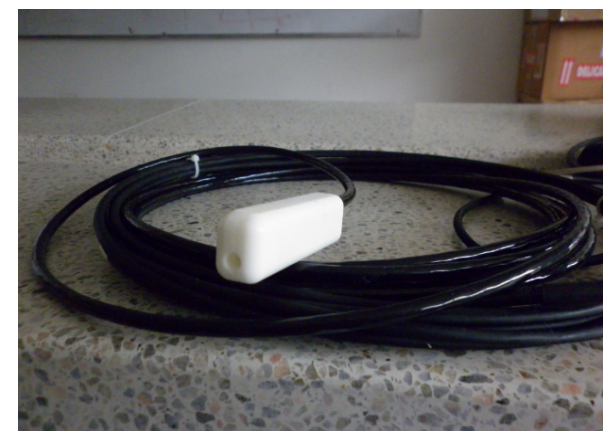

Fig. 6. Sonda de temperatura y Conductividad CS547A - $l$.

Para él envió de señales al CR100 se requiere de la interface A547 (ver figura 7) que proporciona el acondicionamiento de señales en las resistencias de terminación tipo puente que posee el sensor.

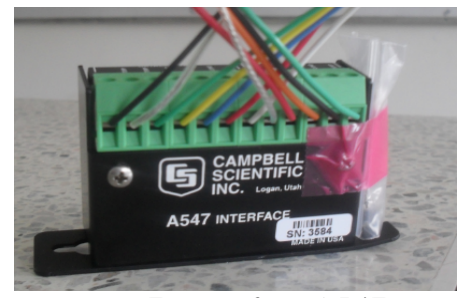

Fig. 7. Interfase A547.

CSIM 11 - L: El sensor CSIM11 de la Campbell [12] (ver figura 6) mide el rango de $\mathrm{pH}$ presente en el líquido dentro del digestor, este lo podemos sumergir en agua, tuberías y canales abiertos. Pero está diseñado para sistemas no presurizados y no podemos utilizarlo en aplicaciones por encima de 30 psi, el rango práctico de la sonda en el cual podemos trabajar es de -700 a $1100 \mathrm{mV}$.

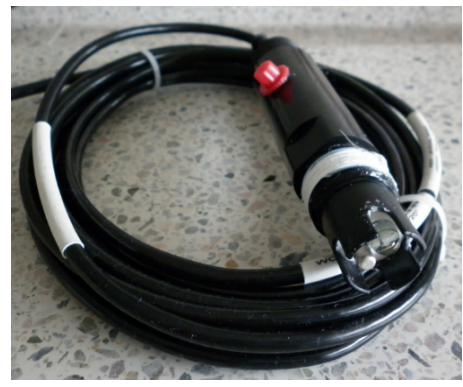

Fig. 8. Sonda de pH CSIM11 - l.

\subsection{Panel Graficas de Dispersión}

Mediante este panel se muestra en tiempo real los datos de la planta provenientes de los sensores, a través de gráficos que nos permiten una lectura más fácil de interpretar ya que muestra la fecha e intervalo ( 1 hora) con que se exploran los dato como se muestra en la figura 9. Se puede visualizar el rango de medición de acuerdo a la variable que se monitorea, a su vez se muestran unos labels e indicadores donde se observa el nombre y valor en tiempo real de la medición de la variable.

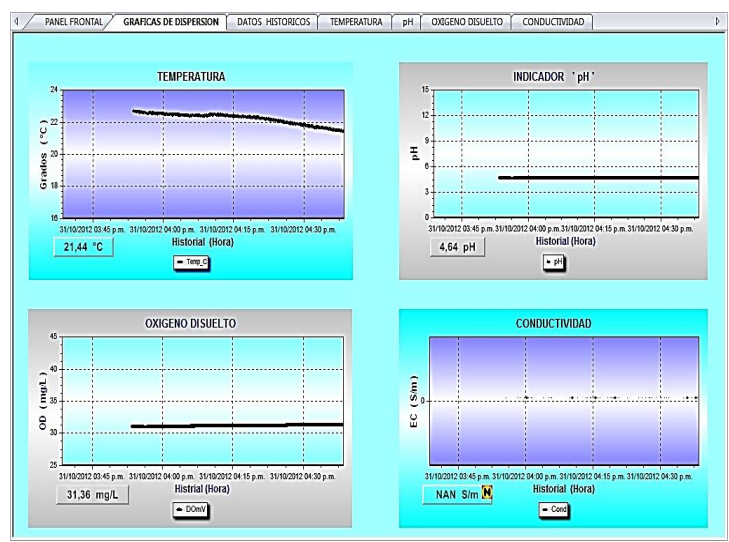

Fig. 9. Panel Gráficas de dispersión. 


\subsection{Panel datos históricos}

A través de este panel el usuario puede observar el comportamiento de cada una de las variables teniendo en cuenta la fecha, hora, nombre e intervalo de exploración de los datos en tiempo real provenientes del Datalogger CR1000 (ver figura 10), la tabla de datos históricos tiene la capacidad para la recolección de 5000 datos por variable, este almacenamiento de datos es una poderosa herramienta para la optimización y corrección de procesos. Además posee indicadores, labels e imagines donde se puede observar de una forma más amigable el comportamiento de cada una de las variables.

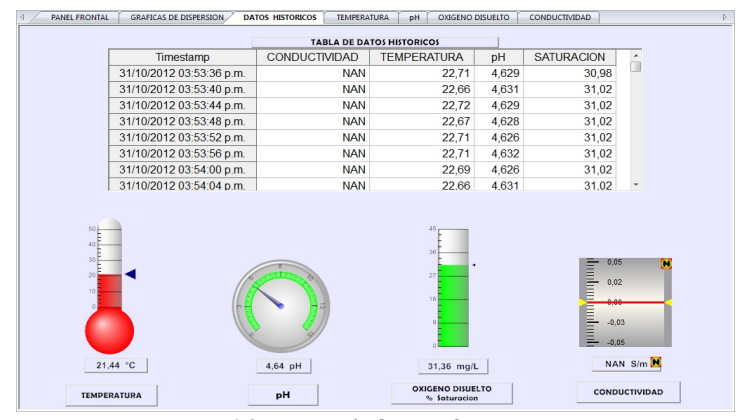

Fig. 10. Panel datos historicos.

\subsection{Paneles para la observación de cada variable}

En cada uno de estos 4 paneles visualizamos individualmente el comportamiento de cada variable (Temperatura, $\mathrm{pH}$, oxígeno disuelto. conductividad) donde se obtienen las graficas de dispersión, tabla de datos históricos, indicadores y labels que nos ayudan a entender la influencia de cada variable dentro del proceso, como se muestra en la figura 11. De igual forma, se tiene los indicadores de alarma para cada variable permitiendo así reconocer eventos excepcionales dentro del proceso y reportar los eventos a un correo electrónico específico. Las alarmas son reportadas basadas en límites de control preestablecidos.

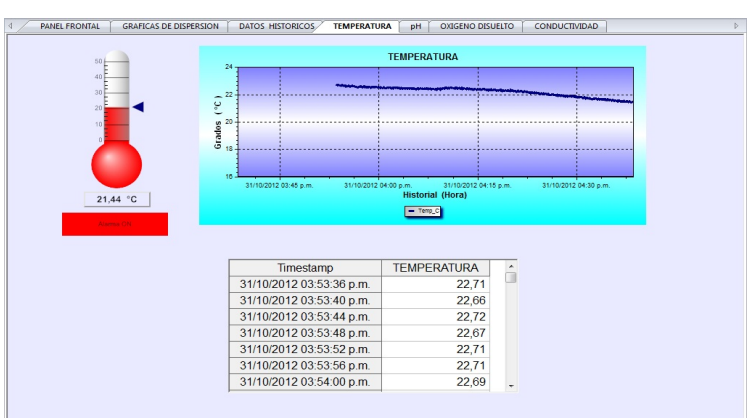

Fig. 11. Panel de observacion para cada variable.

\subsection{Panel comparación de la temperatura respecto a las demás variables}

Debido a que la temperatura es la variable de mayor influencia durante el proceso; se decide crear un panel adicional en el cual se visualizó la comparación de la temperatura respecto a cada variable y así entender de una forma más clara la importancia de la temperatura en la digestión anaeróbica, a su vez cada panel posee imágenes, labels e indicadores donde se observó el comportamiento (ver figura 12).

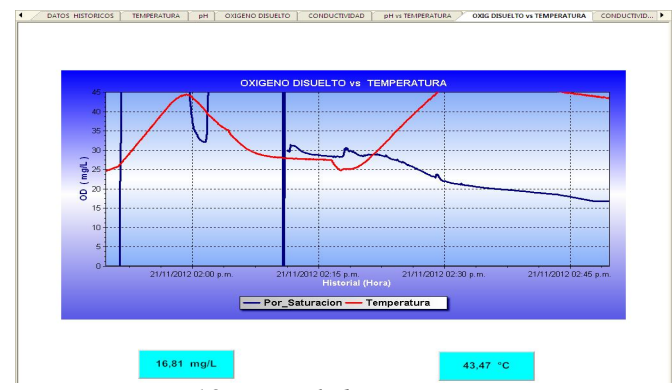

Fig. 12. Panel de comparación.

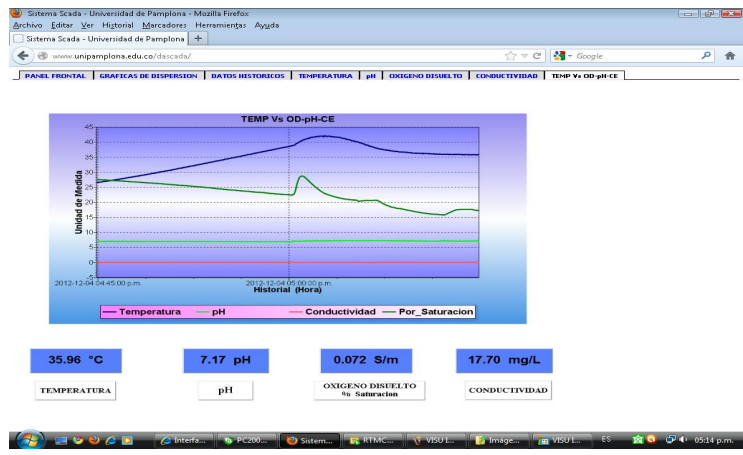

Fig. 13. Visualizacion panel de comparación en la Web.

\section{RESULTADOS Y DISCUSIÓN}

Se va a utilizar el biodigestor tipo autoclave en las prácticas de laboratorio de la asignatura de Cinética química de Bioprocesos para estudiantes de los programas de Ingeniería Química y Ambiental respectivamente. El sistema utilizará sustratos sintéticos que guarden relación según la siguiente distribución.

$$
\begin{gathered}
\mathrm{C} / \mathrm{N} / \mathrm{P} / \mathrm{S} \\
100 \mathrm{gr}-20 \mathrm{gr}-10 \mathrm{gr}-1 \mathrm{gr}
\end{gathered}
$$

De igual forma, se utilizaran para sintetizar el sustrato biomasas (aceto bacter, nitro bacter, sulforeductoras, levaduras) de origen sintético cultivadas previamente (duración del cultivo 15 
días) en el laboratorio de microbiología de la Universidad de Pamplona con un rango de temperatura entre $35^{\circ} \mathrm{C}-40^{\circ} \mathrm{C}$, las fuentes para sintetizar el sustrato son de 4 tipos (fuente de carbono, nitrógeno, fosforo y azufre) cada una de estas fue aplicada en fases.

Previamente se ha puesto en marcha el sistema de monitoreo y comunicación entre Datalogger - PC. Posteriormente se llenó con agua el recipiente de la zona de mezclado, al cual se agregó la fuente de carbono (glucosa C6H12O6) en una cantidad de $100 \mathrm{gr}$, posteriormente esta es colocada dentro del reactor el cual es tapado y sellado, luego se activa el switch que enciende la resistencia de la zona de calentamiento previamente llenada con agua.

Luego se llevó la biomasa al rango de temperatura optima $\left(35^{\circ} \mathrm{C}-40^{\circ} \mathrm{C}\right)$ para la degradación de los sustratos como se observa en la figura 14, posteriormente se estabilizo el pH en 7 (ver figura 14) adicionando un ácido (ácido sulfúrico H2SO4, ácido nítrico $\mathrm{HNO} 3$ o ácido clorhídrico HCI) y una base de (hidróxido de sodio $\mathrm{NaOH}$ o hidróxido de potasio $\mathrm{KOH}$ ) según corresponda respectivamente estabilización de pH como se muestra en la fig. 15.

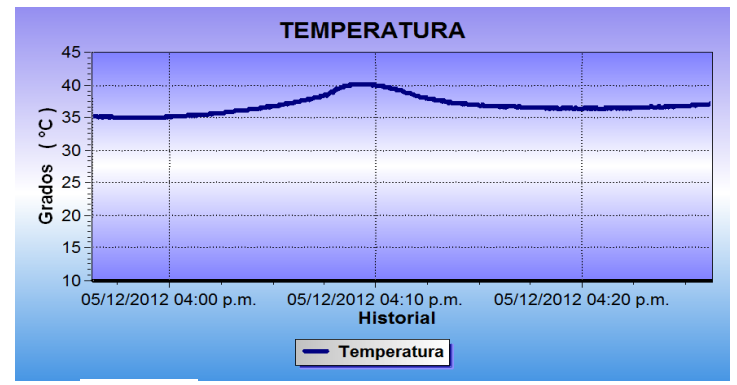

Fig. 14. Temperatura óptima estabilizada.

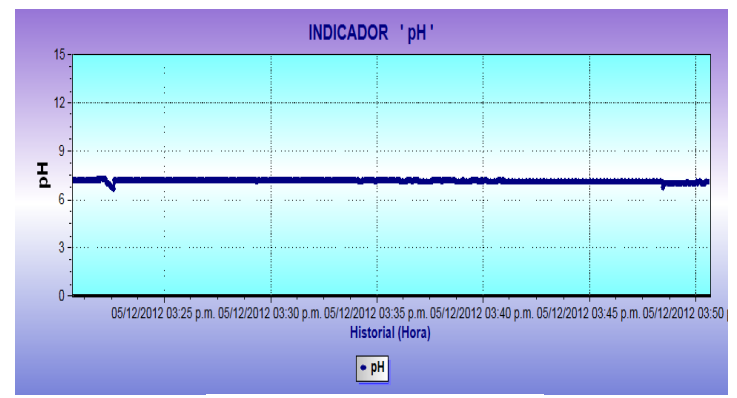

Fig. 15. pH estabilizado

Después de estabilizar el pH se agregó una cantidad de fuente de nitrógeno en este caso Nitrato de amonio (NH4NO3) según la relación anterior, se diluyo la cantidad en un volumen de agua deseado y posteriormente se vierte en el reactor.
De igual forma para las fuentes de fosforo (Dihidrogeno fosfato de potasio $\mathrm{KH} 2 \mathrm{PO} 4)$ y de azufre (sulfato de magnesio $\mathrm{Mg} \mathrm{SO} 4 \cdot 7 \mathrm{H} 2 \mathrm{O}$ ) fueron agregadas después de agregar las fuentes de carbono, se observó cambios significativos en las variables de Oxígeno disuelto, $\mathrm{pH}$, conductividad debido al incremento de iones presentes en la solución dentro del biodigestor (ver figura 16), una vez agregados los nutrientes (nitrógeno, fosforo, azufre) según la relación preestablecida se procedió a inocular el sistema con la bacteria (aceto-bacter aceti) que degrado el sustrato sintético.

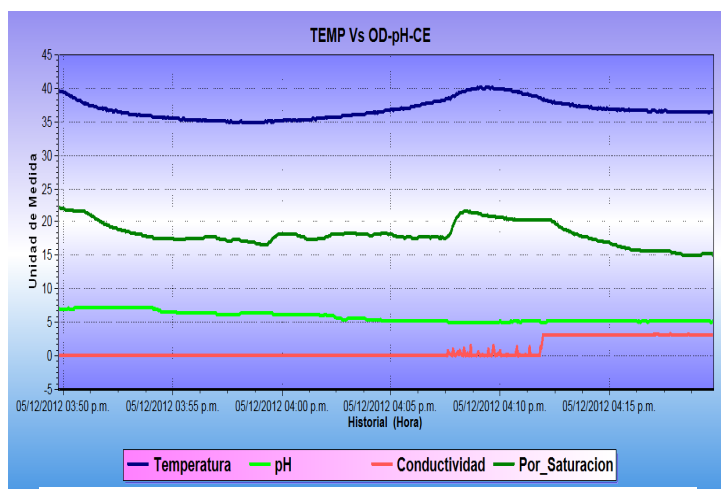

Fig. 16. Comportamiento de las variables en el tiempo.

Se observó que las variables de $\mathrm{pH}$ disminuyen progresivamente por debajo de 5 aumentando el grado de acides (ver figura 17) de igual forma la conductividad y el oxígeno disuelto, por lo tanto se debe estabilizar el $\mathrm{pH}$ cercano a 7 con el fin de que los microorganismos procesen el sustrato en condiciones óptimas del proceso. Se observaron cambios cada 3 segundos el cual fue registrado por el sistema SCADA al cabo de 2 horas se finaliza el proceso y se verifica que se haya degrado la cantidad de sustrato inicial a través de un análisis de carbono orgánico total que se realizó en el laboratorio de control y calidad de la Universidad de Pamplona.

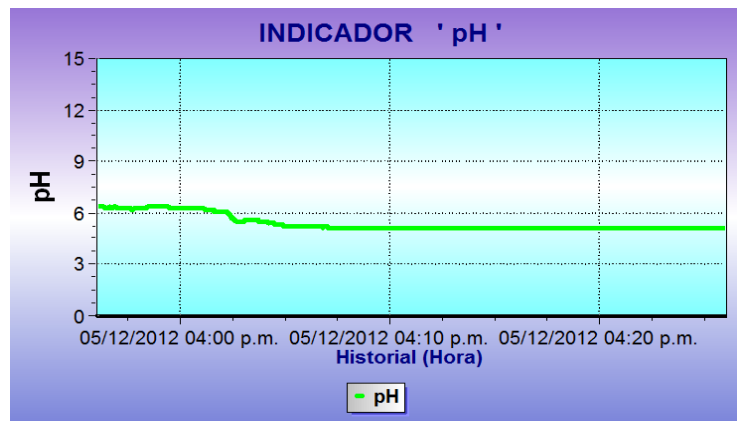

Fig. 17. pH al inocular el sistema. 


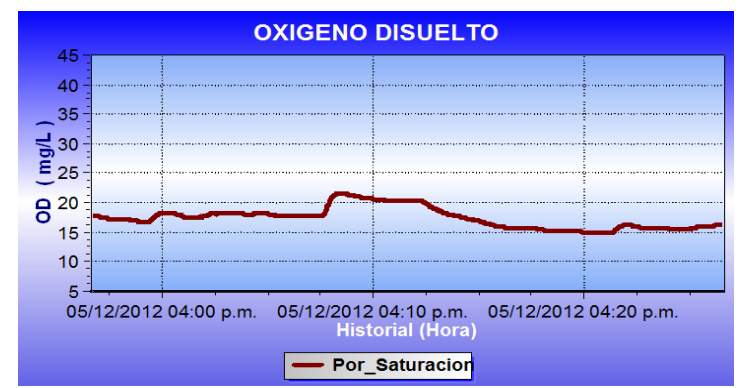

Fig.18. Oxígeno disuelto al inocular el sistema.

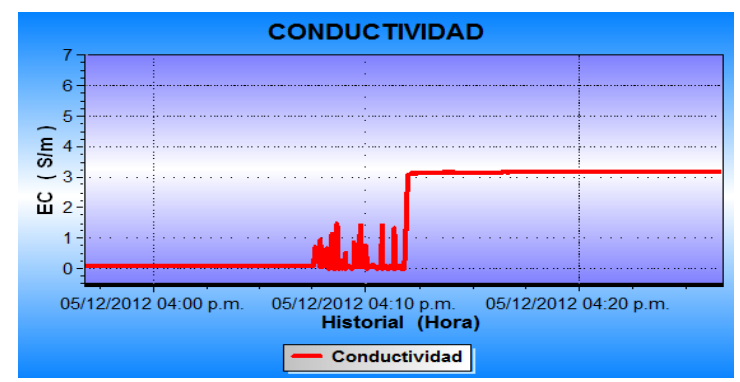

Fig.19. Conductividad al inocular el sistema.

\section{CONCLUSIONES}

Según las características mostradas del hardware se pudo observar que el CR1000 es un registrador de datos para control y adquisición de datos con grandes prestaciones, pues tiene varias entradas salidas, analógicas y digitales, que nos permiten realizar automatizaciones a gran escala. De igual forma, los programas se almacenen en su memoria interna para que el proceso siga funcionando incluso cuando el computador no esté conectado.

El software RTMC nos proporciona una infinidad de herramientas que pueden ser utilizadas para automatizar cualquier proceso a nivel industrial y académico. Utilizando el software RTMC el operador tiene la visualización en tiempo real del proceso, logrando de esta manera la optimización y corrección de algún error presente, obteniendo resultados con mayor eficiencia.

El funcionamiento del sistema de monitoreo desarrollado cumplió con lo requerido, se logró medir las variables aplicadas (temperatura, $\mathrm{pH}$, oxígeno disuelto, conductividad) al proceso, al controlar los actuadores se realizaron las pruebas necesarias.

Se pudo comprobar al realizar las prácticas de laboratorio que el reactor cumplió con las expectativas esperadas monitoreando y controlando las variables del proceso para diferentes tipos de sustratos y crecimientos celulares.

\section{REFERENCIAS}

[1]. Ostrem K. (2004). Greening waste anaerobic digestion for treating the organic fraction of municipal solid waste. M.S. thesis in Earth Resources Engineering. Columbia University.

[2]. Speece R. E. Anaerobic Biotechnology for industrial Wastewater (1996). Archae Press, Nashiville Tennessee, USA

[3]. Vavilin, V. A. and Angelidaki, I. (2005). Anaerobic degradation of solid material: Importance of initiation centers for methanogenesis, mixing intensity, and 2D distributed model, Biotechnology and Bioengineering, 89, (1), 113-122.

[4]. Naciones Unidas (UN). Glosario de Términos Ambientales, citado por Comunidad Andina. Manual de Estadísticas Ambientales. CAN: Santa Cruz de la Sierra, 2005. p 31-45.

[5]. www.galeon.com/hamd/pdf/scada.pdf $(10 / 08 / 2012)$

[6]. http://www.campbellsci.com/pc200w $(09 / 15 / 2012)$.

[7]. http://s.campbellsci.com/documents/us/manual s /loggernet.pdf (09/15/2012).

[8]. Human Machine Interface - What is Human Machine Interface? - AutorDesconocido WisGEEK community

http://www.wisegeek.com/what-is-humanmachine-interface.htm

[9]. ftp://ftp.campbellsci.com/pub/csl/outgoing/es/l eaflets/Curso_CR1000_LoggerNet_castellano. pdf $(09 / 15 / 2012)$.

[10]. http://s.campbellsci.com/documents/us/ma nuals/cs511-1.pdf (09/17/2012).

[11]. http://s.campbellsci.com/documents/ca/ma nuals/cs547a_man.pdf (09/17/2012).

[12]. http://s.campbellsci.com/documents/us/ma nuals/csim11.pdf (09/17/2012). 